\title{
Efficiency of U.S. Hospitals between 2001 and 2011
}

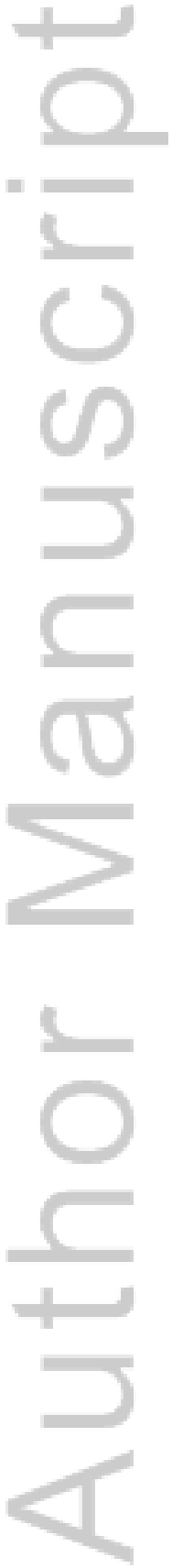

\author{
Jeong Hoon Choi*, Ph.D. \\ Assistant Professor \\ University of Nebraska Kearney \\ College of Business and Technology \\ 2504 9th Ave \\ Kearney, NE, \\ United States
}

Tel: 308-865-8478 / Fax: 308-865-8387

Email: choijh3@unk.edu

Sima M Fortsch, Ph.D.

Assistant Professor

Supply Chain and Operations Management

School of Management

University of Michigan-Flint

Flint, MI 48502-1950

United States

Email: sfortsch@umflint.edu

Imsu Park, Ph.D.

State University of New York at Buffalo

School of Management

Operations Management and Strategy

326F Jacobs Management Center

Buffalo, NY, 14260-4000

United States

Email: imsupark@buffalo.edu

Ilyoung Jung, Ph.D.

Science and Technology Policy Institute

Sejong National Research Complex 370

Sejong City 30147

Republic of Korea

Email: iljung@ @stepi.re.kr

${ }^{*}$ Corresponding Author

This is the author manuscript accepted for publication and has undergone full peer review but has not been through the copyediting, typesetting, pagination and proofreading process, which may lead to differences between this version and the Version of Record. Please cite this article as doi: $10.1002 /$ mde.2846

This article is protected by copyright. All rights reserved. 


\section{Efficiency of U.S. Hospitals between 2001 and 2011}

\section{Abstract}

This study focuses on finding the trend of efficiency in the healthcare industry in recent years. We applied stochastic frontier (SFA) and data envelope analyses (DEA) methods to capture the efficiency of 1,471 hospitals and found a sign of the Baumol effect which is detected by the decreasing trend of hospital efficiency with increasing trend of labor costs. Furthermore, we compared the results of both approaches (SFA and DEA) in capturing efficiency scores and suggest the U-shaped curve of the size effect may indicate the practice of 'cream-skimming' by some small hospitals.

Keywords: Stochastic cost frontier analysis, Data envelopment analysis, the Baumol effect.

This article is protected by copyright. All rights reserved. 


\section{Introduction}

Several studies indicate hospital efficiency has increased significantly since the implementation of Medicare's Prospective Payment System (PPS) in 1983 (Long et al. 1987, Cromwell and Pope 1989). The PPS is a reimbursement method in which service payment is a predetermined fixed amount based on the classification of the task. PPS has a built-in incentive for providers to deliver patient care efficiently without over utilization of services. This is different than conventional fee-for-service payment systems, which may cause unnecessary treatment sessions that must be justified. As a result of PPS, the 'average length of hospital stay' and the 'cost per discharge' significantly decreased over the decade ending in 1996 (Ashby, Guterman, and Greene 2000). Moreover, the cost containment measures introduced during the era of 'managed care' are also believed to have reduced total 'hospital costs'. These changes motivated many scholars to study the efficiency of hospitals across the nation. Despite the fact that during the mid-1990s hospital costs steadily increased, many studies showed that hospital efficiency improved. As an example, Rosko (2001) found that the average cost inefficiencies of 1,631 U.S. hospitals decreased from 1990 to 1996 , which indicates efficiency improvements.

Some scholars have argued that the effect of external impacts such as policy changes could be diluted due to the labor-intensive nature of the healthcare industry. For example, Baumol and Bowen (1966) argue it might be difficult to obtain actual productivity or efficiency growth in the healthcare industry because hospitals' main inputs are labor rather than technology. The authors anticipated that the increase in the labor price could possibly offset (or even diminish) the value of the realized efficiency. In other words, for a labor-intensive industry, a rise in salaries could disrupt and delay productivity or efficiency growth. This phenomenon is known as 'the Baumol effect', which has received much attention for study in the healthcare industry. The Affordable Care Act, which is expected to expand health insurance coverage to more than 30 million uninsured Americans without increasing the federal deficit, has made it necessary to improve the efficiency of hospitals, which would enable the delivery of affordable high-quality 
healthcare. Hence, it is essential to accurately measure efficiency over time to understand the pay-for-performance scheme in the healthcare sector (Rosko and Mutter 2008).

Due to the fact that most studies focused on hospital efficiency were conducted in the early- to mid-1990s immediately following the PPS policy changes, as well as the adverse impact suggested by the Baumol effect, this study focuses on finding the trend of efficiency in the healthcare industry in recent years. Therefore, we obtained a new dataset from 1996 through 2011 to capture the delayed outcomes. Furthermore, we measure the efficiencies using two different methods, stochastic frontier and data envelope analyses (SFA and DEA). Although the SFA and DEA have been studied individually, we found few studies in the current literature that compare these two methodologies. Moreover, we group hospitals based on their control type, teaching/non-teaching status, and size to measure efficiencies that could help policymakers regarding critical decisions.

The rest of this paper is organized as follows. The next section summarizes a literature review regarding efficiency measurement in the healthcare industry. Section 3 introduces the study's data sources and explains SFA and DEA methodologies, while Section 4 summarizes the empirical results, followed by a discussion of results in Section 5 . Finally, Section 6 reviews the conclusion and possible extensions for future research.

\section{Literature Review}

Accurate performance measurements lead to significant improvements in hospital care, quality, and costs (Kaplan and Porter, 2011). Literature indicates many researchers have applied various approaches to study hospital performance, including ratio analysis, ordinary least squares (OLS) regression, and corrected ordinary least squares (COLS) regression. Some of these techniques, however, have several disadvantages. In ratio analysis, for example, 
the output depends on arbitrary efficiency criteria or cutoff points such as a quarter-percentile point or median (Rosko and Mutter, 2011). Similarly, OLS regression might have a biased intercept or error term (Kumbhakar and Lovell, 2000; Rosko and Mutter, 2008). Correspondingly, the two-stage COLS regression allows the regression line to pass through the observation points that have the smallest residual, which permits the actual regression line to be shifted. Consequently, COLS regression might contain a biased intercept or error term, and allows the estimated frontier line to be parallel to the OLS regression (Rosko and Mutter, 2008).

Due to the shortcomings of the above models, the frontier approach has often been applied to measure the efficiency of hospitals. The frontier approach is divided into two types: stochastic frontier analysis (SFA), which is a parametric approach, and data envelopment analysis (DEA), which is a non-parametric, mathematical method. Aigner et al. (1977) and Meeusen and van den Broeck (1977) introduced SFA as a form of production function to estimate productive inefficiency. SFA decomposes the estimated error term into two components, inefficiency and random error, while OLS cannot estimate inefficiency. In microeconomics, scholars use either a production frontier or a cost frontier to measure the inefficiency of a decision-making unit (DMU). Hence, SFA is divided into the stochastic 'production' frontier analysis (SPFA) to maximize production, and the stochastic 'cost' frontier analysis (SCFA) to minimize costs.

In the healthcare industry, SCFA (the cost minimization approach) is often the preferred method of measuring efficiency for the following reasons. First, a hospital's production process is difficult to define. In contrast to manufacturers with standardized production lines, hospitals confront considerable variations in how and what outputs are produced (Hollingsworth and Street, 2006). Second, a production frontier function (i.e., SPFA that focuses on production) allows using only one output measure as a dependent variable, while a cost frontier function (SCFA that focuses on costs) allows multiple output measures. Since hospital outputs have been measured in multiple dimensions, including some non-monetary measures, scholars often favor the SCFA approach. Furthermore, the 
SCFA model shifts the cost frontier model to an appropriate level by adjusting intercepts, while the intercept of the OLS might be overestimated (Linna and Hakkinen, 1998; Rosko, 2001).

DEA was introduced by Charnes et al. (1978) and further developed by Banker et al. (1984). This non-parametric, mathematical programming technique determines the frontier line based on the location of the best-practice DMU. DEA is divided into two major models, one which assumes constant returns to scale (CRS) and the other which allows variable returns to scale (VRS). Generally, the VRS model is preferred in two cases: when the size effect is expected because CRS assumes no relationship between scale and efficiency, and when a mixture of index and volume measures is employed as outputs or inputs. The mixture might cause a biased estimation in the CRS model, whereas the VRS model presents no such a problem (Banker and Morey, 1986; Hollingsworth and Smith, 2003; Korhonen and Syrjanen, 2004). DEA is also divided into an input-oriented model and an output-oriented model. Efficiency can be increased by minimizing inputs while maintaining outputs (input-oriented approach) or maximizing outputs while maintaining inputs (output-oriented approach). For the CRS method, the input- and output-oriented approach should generate identical results, while the two approaches do not generate equivalent outcome for the VRS. Therefore, the VRS method is sensitive to the selection of the approach chosen by the scholar (i.e., input- or output-orientation). Although it is unclear whether all hospitals view either inputs or outputs (Burgess and Wilson, 1996), input-oriented models have frequently been applied in research because one would have more control over costs (input-oriented) than the number of outputs (O'Neill et al., 2008). In this study, the input-oriented DEA approach is used, and the goal is to reduce inputs with fixed output levels.

SFA and DEA both have advantages and disadvantages. For example, SFA can account for statistical noise and is more likely to assess efficiency related to additional or control factors. SFA is used to estimate the effect of exogenous or control variables on efficiency. SFA, though, has been criticized for using strong assumptions for decomposing inefficiency and random error (Newhouse 1994) and is known to have three major disadvantages: (1) It 
requires specifications of the functional form of the cost function; (2) different choices of functional forms and the distribution of composed errors can affect estimated efficiencies; and (3) it cannot identify the sources of inefficiencies (Folland and Hofler, 2001; Rosko and Mutter, 2008). Advocates of DEA contend that it avoids strong assumptions by empirically determining the shape and the location of the frontier. Another benefit of DEA, given the nature of healthcare service, is its applicability to multiple inputs and outputs (Hollingsworth et al., 1999). It is also vulnerable to unusual types of DMUs (outliers), which might result in inappropriate positioning of the frontier (Hollingsworth and Street, 2006). There are no standard diagnostic tools to judge the goodness of fit of the model specification (Jacobs, 2001).

SFA and DEA have been applied separately to measure hospital efficiencies in numerous studies. However, there is a lack of studies comparing the efficiencies estimated by these methods. In addition, earlier comparative studies have reported conflicting results for the efficiencies estimated by SFA and DEA methods. Therefore, it would be beneficial to compare the two frontier methods for the healthcare sector. Although several studies argue that DEA and SFA might be a close substitute due to the correlation between the two, despite some public sector such as airport industries, this correlation has not been strong for the healthcare sector (Zhuo et al., 2013). Jacobs (2001), for example, found a correlation of $0.42-0.63$ in a study of 232 English hospitals, and Linna and Hakkinen (1998) reported a correlation of $0.28-0.59$ in a study of 95 Finnish hospitals. Similarly, Chirikos and Sear (2000) studied 186 U.S. hospitals and found a correlation of $0.13-0.33$, and reported opposite efficiency results from the SFA and DEA methods. The magnitude of the correlation between SFA and DEA methods could also be due to the size of the selected hospitals. On the other hand, several scholars have argued that the differences between the above two methods might also be due to the underlying assumptions in SFA and/or the DEA's sensitivity to outliers. Thus, some scholars have suggested combining the two methods (Banker, 1993).

We summarize the literature on efficiency based on hospital types in Table 1. 


\section{Insert Table 1 here}

\section{Methods}

\subsection{Data Sources}

Hospital data were collected from the Centers for Medicare \& Medicaid Services' (CMS) Medicare Cost Report datasets. Medicare Cost Reports are submitted annually by all healthcare service providers participating in the Medicare program. We focused on general and medical-surgical hospitals with more than 25 beds to maintain, consistency with previous literature on efficiency measurements. Panel data from 1,471 hospitals covering from 2001 to 2011 is obtained, and all the monetary values are adjusted by the Producer Price Index (PPI).

We separated the hospitals using different classification criteria (i.e., control type, teaching/non-teaching status, and size) to analyze hospital efficiency. The U.S. healthcare sector is one of a few industries in which not-for-profit, forprofit, and government providers exist in significant proportions (Burgess and Wilson, 1996; Goldstein et al., 2002). For-profit hospitals are privately owned and run hospitals, whereas not-for-profit hospitals are operated by voluntary and charity groups. Government hospitals are run by federal, state, or municipal governments. Not-for-profit hospitals must comply with certain legal restrictions, including spending any profits in designated areas such as education, charity, and religious service. This constraint makes a fundamental difference between for-profit and notfor-profit hospitals (Sloan, 2000; Rosko and Mutter, 2011). When considering teaching status, teaching hospitals are characterized by: (1) a transient workforce consisting mostly of residents and students, and (2) research and medical education (Stevens, 2004; Huckman and Barro, 2005; Theokary and Ren, 2011). The size of hospitals has been another critical issue in hospital efficiency studies considering learning effect and economies of scale. Table 2 shows the summary of hospital statistics. 


\section{Insert Table 2 here}

For the analyses of different groups, the results are grouped by hospital classification criteria: control type, teaching/non-teaching status, and size. The control type is guided by the CMS and the American Hospital Association (AHA) classification criteria for not-for-profit, for-profit (proprietary), and government hospitals. Teaching/non-teaching status is based on the Hospital and Hospital Health Care Complex Identification Data worksheet of the Medicare Cost Report. The size criterion is adopted from the AHA's classification. Hospitals are divided into five groups based on number of beds. The hospital classification system and basic statistics regarding classification are shown in Table 3. The dataset covers all types and sizes of hospitals taking into consideration teaching status in all U.S. regions.

\section{Insert Table 3 here}

\subsection{Inputs and Outputs}

To measure efficiency, many scholars have proposed various inputs and outputs, but with several limitations. The inconsistency in using inputs and outputs in the healthcare industry has made it difficult to accurately measure hospitals' level of efficiency from the longitudinal perspective (Cylus and Dickensheets, 2007). Rosko and Mutter (2008) provided a comprehensive discussion of various input and output variables to be used. We employ number of admissions, post-admission days, and the number of outpatient visits as output variables. Admissions and postadmission days represent two categories of inpatient care activity, while the number of outpatient visits indicates outpatient care activity (Zuckerman et al. 1994, Rosko and Mutter 2008). The inpatient care output variables are adjusted by case-mix-index (CMI). We also use a number of product descriptor variables to control output 
heterogeneity, as suggested by earlier studies (Dor and Farley, 1996; Mutter et al., 2008; Rosko and Mutter, 2008). We use CMI and ER\% (emergency room visits as a percentage of total outpatient visits), and OUTSURGERY\% (outpatient surgery as a percentage of total outpatient visits) as our control variables.

SFA and DEA require different sets of variables for inputs. SFA uses price as an input, while DEA uses costs. For both inputs, we calculated the area average price to avoid any endogeneity issues (Dor and Farley, 1996; Rosko, 2004; Mutter et al., 2008). As in previous literature, we used the approximated area average of annual payroll and employee benefits divided by the number of full-time employees [(payroll expense + employee benefits)/number of employees] to proxy wage price. The capital price is approximated by the area average of depreciation and interest expense per bed [(depreciation + interest expense)/number of beds] (Banker et al., 1986; Rosko and Mutter, 2008).

Several DEA-based hospital efficiency studies use capital and labor costs as inputs (Hollingsworth and Smith, 2003). Thus, we stay consistent with literature and use the same two variables as inputs in the DEA model. The three output variables used in the SFA model (i.e., admissions, post-admission days, and number of outpatient visits) are also the same outputs in the DEA model. Additionally, to be consistent with previous studies, we use a mix of inpatient and outpatient care variables (Hollingsworth and Smith, 2003; Hollingsworth and Street, 2006).

\subsection{Methodology And Model Specification}

Regarding the functional form of the cost frontier model, the two most popularly used forms in hospital efficiency studies have been the natural log form of the Cobb-Douglas cost function and the translog cost function (Rosko and Mutter, 2008). The Cobb-Douglas model was originally designed for production functions and can save degrees of freedom by removing the squared and cross-product terms found in the translog form. The translog cost function is a flexible functional form consistent with cost-minimizing behavior (Rosko, 1999; 2001), and contains the quadratic and cross-variable terms. Rosko and Mutter (2008) found that the use of different functional forms had little impact 
on the estimation of hospital efficiency, though different functional forms do not generate identical estimations. However, Rosko (1999) argued that the translog cost function has two advantageous features over the natural log form of the Cobb-Douglas function. First, the translog function places no a priori restrictions on substitution possibilities among production factors. Second, this function allows scale economies to vary with the level of output. Therefore, most previous studies use a translog cost function as the functional form of cost function (Banker et al., 1986; Linna, 1998; Rosko, 2001). In this study, we also apply a translog function as the functional form of cost function. The general form of the translog cost function is expressed as follows:

$$
\begin{aligned}
\ln C_{i t}= & \beta_{0}+\sum_{k=1}^{K} \beta_{1 k} \ln P_{k i t}+\sum_{s=1}^{S} \beta_{2 s} \ln Y_{\text {sit }}+\frac{1}{2} \sum_{k=1}^{K} \sum_{k^{\prime}=1}^{K} \beta_{3 k k^{\prime}} \ln P_{k i t} \ln P_{k \prime i t}+\frac{1}{2} \sum_{s=1}^{S} \sum_{s^{\prime}=1}^{S} \beta_{4 s s^{\prime}} \ln Y_{\text {sit }} \ln Y_{\text {sit }} \\
& +\sum_{k=1}^{K} \sum_{s=1}^{S} \beta_{5 k s} \ln P_{k i t} \ln Y_{s i t}+\varphi P D_{i t}+\varepsilon_{i t} \\
\varepsilon_{i t}= & v_{i t}+u_{i t},
\end{aligned}
$$

where $C_{i t}$ is the adjusted total operating cost, $\mathrm{K}$ and $\mathrm{S}$ are the number of inputs and the number of outputs respectively, $P_{\text {kit }}$ is the price of capital and labor, $Y_{\text {sit }}$ are outputs, $P D_{i t}$ represents control variables, and $\varepsilon_{i t}$ is the sum of random error $\left(v_{i t}\right)$ and inefficiency $\left(u_{i t}\right)$. To estimate hospital-specific efficiency, we use the time-varying decay model proposed by Battese and Coelli (1995). The time-varying decay inefficiency $\left(u_{i t}\right)$ is estimated via timevariant factor $(\eta)$ as

$$
u_{i t}=\eta_{\mathrm{t}} \mathrm{u}_{\mathrm{i}}
$$

where

$$
\eta_{\mathrm{t}}=\exp \left[-\eta\left(\mathrm{t}-T_{i}\right)\right],(t=1,2, \ldots, T)
$$


As shown in these equations, $\eta$ decides the trend of inefficiency. The cost efficiency of $i$-th hospital and $t$-th year can be defined as

$$
C E_{i t}=\exp \left(-u_{i t}\right)
$$

The basic form of input-oriented VRS model is denoted as follows. Let the efficiency measured by the input-oriented DEA model, with the assumption of the variable of returns to scale be denoted by $\theta$. The input price of each hospital is denoted as $P_{m}^{k}$ and the input level is $x_{m}^{k}$, while the output level of the hospital is shown as $y_{n}^{k} . \mathrm{M}$ and $\mathrm{N}$ are the number of inputs and the number of outputs respectively. Let the unknown weight of $\mathrm{j}$-th hospital be $\lambda^{j}$, and $\varepsilon$ be a non-Archimedean number which allows the minimization of $\theta$. Input and output slacks, denoted as $s_{m}^{-}$and $s_{n}^{+}$ respectively, are determined through a two-stage approach. First, the minimum radial efficiency $\theta^{k^{*}}$ is determined. Second, by setting $\theta^{k}$ equal to this minimum $\theta^{k^{*}}$ we determine slacks. This two-stage approach ensures consistency with the desired prioritized optimization in the non-Archimedean specification (Banker et al. 1986). The DEA model is formulated as follows:

$$
\theta^{k^{*}}=\min _{\theta, \lambda, s^{-}, s^{+}} \theta^{k}+\varepsilon\left(\sum_{m=1}^{M} s_{m}^{-}+\sum_{n=1}^{N} s_{n}^{+}\right)
$$

subject to

$$
\begin{gathered}
\theta^{k} P_{m}^{k} x_{m}^{k}=\sum_{j=1}^{J} P_{m}^{j} x_{m}^{j} \lambda^{j}+s_{m}^{-} \\
y_{n}^{k}=\sum_{j=1}^{J} y_{n}^{j} \lambda^{j}+s_{n}^{+}
\end{gathered}
$$




$$
\begin{gathered}
\sum_{j=1}^{J} \lambda^{j}=1 ; \\
\theta, \lambda^{j}, s_{m}^{-}, s_{n}^{+} \geq 0(\mathrm{j}=1,2, \ldots, \mathrm{J})
\end{gathered}
$$

\section{Empirical Findings}

We used several different model specifications, omitting and including different variables, and carried out sensitivity analysis, testing the robustness of models. We found the results of the SFA model are statistically significant based on the test statistics of the log-likelihood test $(16,382.78)$ and the Wald chi-square test $(36,492.31)$. Individual efficiency scores under each method remained relatively stable, which indicates our proposed model specification is robust. Table 4 shows the descriptive statistics for the two sets of efficiency scores estimated by SFA and DEA. The median and mean of the efficiency scores estimated by DEA are higher than those estimated by SFA. DEA sets the performance of the best hospital as the frontier, so the theoretical distance between each DMU's performance and the frontier is closer in DEA than SFA. The standard deviation of efficiencies estimated by the DEA model is greater than in the SFA model. The volatility of the DEA results is theoretically higher than that of the SFA results because outliers easily influence the DEA results.

\section{Insert Table 4 here}

The time variant factor $(\eta)$ of the SFA model is estimated as -.0102 , and the $t$-value $(t=-12.88)$ shows that the estimation is statistically significant (See Appendix 1) and cost efficiency has decreased over the years. In addition, the estimated labor price shows a steadily increasing trend over the period. The decreasing trend of cost efficiency with the increasing labor price may show a sign of the Baumol effect in the healthcare industry. The medians and means of the efficiency scores estimated by the SFA method also show efficiency has decreased over the period studied, as shown in Table 4. The efficiency scores estimated by the DEA method were not used to track the trend of 
efficiency since they are relative measures, which indicate the observed rankings of DMUs. Though there are discussions of time-series decomposition using Malmquist Index approaches on the DEA method, the Malmquist index cannot be simply accumulated over time since the index does not satisfy the transitivity condition in general (Mathur, 2007). The cumulative indexes are likely to be biased (Cortèse and Hua, 2002; Oh et al., 2016).

Spearman's rank correlations are used to compare the efficiencies estimated by two methods. Non-parametric Spearman's rank correlations are preferred over Pearson's correlations for two reasons. First, the efficiency scores estimated by DEA are relative efficiencies, which indicate the observed rankings of DMUs, while the efficiency scores estimated by SFA are theoretical efficiencies. Second, the Shapiro-Wilk test results show the efficiency scores estimated by different models do not have a normal distribution (See appendix 2 and 3). When a sample is not normally distributed, the non-parametric correlation test is preferred because it is valid for any shape that might describe the sampled population. The Spearman's rank correlation coefficient of SFA and DEA efficiency scores is 0.571 in the year 2011. The other years show similar correlations between SFA and DEA results (0.528-0.611) (see Appendix 4). The correlation between SFA and DEA results is not high enough for a perfect congruence between two models, as reported in a number of previous studies. These 'not high enough' correlations have several possible causes. First, the SFA model constructs a theoretical frontier, while the DEA model uses the performance of the most efficient DMU as the frontier. Second, random noise, which might be mistaken for inefficiency in the DEA model, could affect the efficiency estimated. The SFA model can account for statistical noise by decomposing variance into inefficiency and a classical error component. Third, control variables can be added and applied to SFA models while a DEA model rarely holds control variables. Fourth, DEA addresses technical efficiency, while SFA calculates a combination of technical and allocative efficiency, which cannot be separated without adding assumptions to the SFA model (Rosko and Mutter, 2011). 
To compare the efficiency scores of groups of hospitals, the median is used as a measure of the central tendency. Additionally, non-parametric methods such as the Kruskal Wallis H and Mann-Whitney rank sum tests are applied because (1) the efficiency score estimated by DEA is relative and indicates the ranking of each DMU, and (2) the Shapiro-Wilk test results show that the hospital efficiency scores are not normally distributed; hence, non-parametric methods are preferred. The Kruskal-Wallis $\mathrm{H}$ test is a non-parametric approach used to compare more than two samples that are independent or not related. The Mann-Whitney rank sum test is a non-parametric method to test the null hypothesis that two independent distributions are same. In this study, three criteria (i.e., control type, teaching/non-teaching status, and size) are tested. Regarding hospital type, all the results of the Kruskal-Wallis $\mathrm{H}$ test indicate the distributions of all groups' efficiency scores are not equal, regardless of model $(\mathrm{p}<.001)$. However, when two groups of hospitals are compared using the Mann-Whitney rank sum test, the difference between not-forprofit hospitals and government hospitals is not statistically significant, but for-profit hospitals have statistically significant differences with both other types of hospitals (see Appendix 5).

When teaching status is considered, the SFA results indicate teaching and non-teaching hospitals have statistically different efficiency scores for the research period. In the DEA models, the efficiencies of teaching and non-teaching hospitals in recent years are statistically different (see Appendix 6). When hospital size is considered, the KruskalWallis $\mathrm{H}$ test results show that the distributions of all groups' efficiency scores are not equal $(\mathrm{p}<.001)$. Based on the results of the Mann-Whitney test, the different size classifications of hospitals have statistically significant differences with other groups in most cases. Only two tests (i.e., test for SZ1 and SZ2 and test for SZ1 and SZ3) did not result in statistically significant differences with DEA models, while only one test (i.e., test for SZ1 and SZ3) did not show the significant difference with the SFA model (see Appendix 7). Both results indicate the U-shaped curve of the size effect, as explained in a number of previous studies (Theokary and Ren, 2011; Choi et al., 2015). 


\section{Discussion}

As Greene (2008) reported, comparisons show 'not high enough' correlations between efficiency scores estimated by SFA and DEA. As discussed, the Spearman's rank correlations might be caused by a number of factors, such as allocative efficiency. Allocative efficiency consists of choosing the optimal combination of inputs, whereas technical efficiency requires minimizing the quantities of inputs with the chosen quantities of outputs (Fare et al., 1985; 1994). Allocative inefficiency arises when a hospital does not use its resources according to their market prices. Allocative efficiency creates different results when SFA and DEA are applied to measure efficiency because SFA measures cost efficiency, and DEA technical efficiency.

Comparing groups of hospitals by the efficiencies calculated using these two methods suggests implications interesting to hospital stakeholders and policymakers. Figure 1 shows the box-plot of 2011 efficiency scores by hospital type, teaching status, and size. Though comparisons between efficiency scores estimated by SFA and DEA show 'not high enough' correlations, the majority of comparison results among groups of hospitals are qualitatively comparable. The comparison of results based on control type shows consistency across the models. The median of all efficiency scores regardless of model indicates for-profit hospitals are more efficient than the other two types of hospitals (see Appendix 8). This result supports the majority of earlier studies finding that for-profit hospitals are more efficient because non-profit hospitals and government hospitals do not maximize profit. Not-for-profit hospitals must spend profits on charity care, research, teaching, and reinvestment in facilities. The public ownership of government hospitals can induce a distorted perception of market prices. Considering teaching/non-teaching status, though, produces different results (see Appendix 9). When the SFA model is used, non-teaching hospitals show higher efficiency, while DEA model results indicate the opposite. If allocative efficiency is a major cause of the difference, the opposite results imply that teaching hospitals have higher technical efficiency, and non-teaching 
hospitals higher cost efficiency. Teaching hospitals are more costly due to high research and education costs, so their nature might prevent them from achieving allocative efficiency.

\section{Insert Figure 1 here}

The comparison gains more value when considering hospital size (see Appendix 10). In both models, larger hospitals mostly show higher efficiency, but the smallest hospital group has higher efficiency than the next-smallest group, so the overall results have a U-shaped curve. The median scale economy in the DEA model, measured by a ratio of CRS to VRS, is 0.882 , which implies that increasing scale might raise efficiency by up to $12 \%$. The higher technical efficiency of larger hospitals is explained by economies of scale, which numerous researchers have pointed to as the primary reason for the higher performance of larger hospitals. For example, Porter and Teisberg (2004) expect larger hospitals to be more efficient than smaller hospitals mainly due to the learning effect and economies of scale. The Ushaped curve of the size effect may be explained by the proliferation of small hospitals which act like special hospitals though they are not, and might account for the trend toward higher cost efficiency among small hospitals. According to the CMS, specialty hospitals are "are primarily or exclusively engaged in the care and treatment of: (1) patients with a cardiac condition; (2) patients with an orthopedic condition; or (3) patients receiving a surgical procedure." Many small hospitals treat patients with less-complicated cases and lower acuity, and a high proportion of patients with generous insurance coverage (Greenwald et al., 2006; Cram et al., 2008). Some small hospitals might send patients with emergency conditions to bigger hospitals and be unable to effectively manage emergency care. On the other hand, general hospitals deliver subsidized, unprofitable services, while in small hospitals, patients with the most financial sources rely on profitable services and patient treatments. In fact, higher CMI is associated with larger hospitals. Hospitals are required to see all patients regardless of cost or the severity of patients' illness, but some hospitals prefer more profitable, less-complicated, and well-insured patients. This practice is called cream-skimming,

or the selection of more lucrative patients or those seeking more profitable treatments. The entry of specialty 
hospitals reportedly has had adverse effects on the financial viability of general hospitals and their ability to provide services to financially vulnerable customers (Ellis, 1998). In addition, the high portion of for-profit ownership among smaller hospitals might lead to physician self-referrals and overutilization of services (Greenwald et al., 2006). Some specialty hospitals can focus on a single line or limited numbers of services and, consequently, achieve efficiency gains. Legal restrictions and competition in the labor market might add to the inefficiency of large hospitals.

\section{Conclusion}

This research examines the cost efficiency of US hospitals longitudinally and found the diminishing trend of the efficiency. Combined with increasing trend of labor costs, the finding of this research shows a sign of the adverse effect suggested by Baumol and Bowen (1966), who contended that it is difficult to attain productivity or efficiency growth in a labor-intensive industry. This study measured efficiency using both SFA and DEA, and compared efficiency scores of groups of hospitals. Though correlations of efficiency scores estimated by two methods were not high enough, the comparison results indicate the similar signs when control type and size are considered. For-profit hospitals show the higher efficiency than the other counterparts regardless of the measurement methods. In congruence with previous studies, this study found a U-shaped size effect when hospitals were grouped by size. However, the SFA and DEA generate different results when teaching/non-teaching status was considered. The different result may indicate the effect of allocative efficiency as explained before.

This study calls for future research to address its limitations. First, the Baumol effect needs to be more thoroughly investigated since it seems that this effect exists in the present investigation. Second, the correlations between efficiency scores measured by SFA and DEA methods are 'not high enough'. Such 'not enough high' correlations may be caused by outliers or random noises which are treated differently. Furthermore, the mechanism to generate the difference between efficiency scores estimated by two methods has not been clearly investigated. This is one of 
the reasons discouraging comparison studies between two models. Future studies need to scrutinize the complex mechanisms of both models and explain differences of those models more concretely. Third, allocative efficiency in the healthcare industry needs to be investigated. The issue of allocative efficiency arises when different prices or unit costs are associated with the performance of different DMUs. With the same level of input, a hospital that treats less costly patients might show higher allocative efficiency. Fourth, it would be of interest to capture the dynamic changes over time using the DEA-oriented model. This research can be extended by adopting appropriate a DEArelated longitudinal model and consider the time dimension of relative efficiency. Finally, this research can be extended by including more output and control variables in the SFA model. Measurements of cost efficiency that do not consider quality variables might be vulnerable to omitted variable bias (Carey, 2003; Folland and Hofler, 2001). Quality needs to be considered as is done in other service industries (Soteriou and Zenios, 1999). In the healthcare industry, quality of care has been measured in three broad ways (Donabedien 2003; Romano and Mutter 2004). The first way is to use structural variables that describe the conditions of hospitals. Though structural measures are easy to apply, they explain little of the observed variability in processes and outcomes, which are direct concerns of customers. Furthermore, it is hard to examine the dynamic and complex features of quality of care in hospitals through the use of structural variables. The second way is to use process measures that describe the content of healthcare and include all healthcare providers' activities. Process measures are appropriate quality measures to elucidate the mysterious care process, but it is more expensive to collect process measures than other quality measures. Use of process measures also requires developing standard measures that can be universally applied to hospitals. The third way is to use outcome measures as quality variables. Outcome measures typically address mortality, which is of considerable interest to consumers as ultimate outcome measures, but are solely determined by the ultimate outcomes. Considering the characteristics of quality of care, future researchers need to incorporate 
quality in addition to efficiency in health care industry. Future studies on this topic could better guide hospital managers and policymakers in measuring the efficiency of hospitals.

\section{References}

Aigner DJ, Lovell CA, Schmidt P. 1997. Formulation and estimation of stochastic frontier production models. Journal of Econometrics 6(1): 21-37.

Arrow KJ. 1963. Uncertainty and the welfare economics of medical care. American economic Review 53: 941-973.

Ashby J, Guterman S, Greene T. 2000. An analysis of hospital productivity and product change. Health Affairs 19(5): 197-205.

Banker RD. 1993. Maximum likelihood, consistency and data envelopment analysis: A statistical foundation. Management Science 39(10): 1265-1273.

Banker RD, Charnes A, Cooper WW. 1984. Models for estimation of technical and scale inefficiencies in data envelopment analysis. Management Science 30: 1078-1092.

Banker RD, Conrad RF, Strauss RP. 1986. A comparative application of data envelopment analysis and translog methods: An illustrative study of hospital production. Management Science 32(1): 30-44.

Banker RD, Morey RC. 1986. Use of Categorical Variables in Data Envelopment Analysis. Management Science 32(12): 1613-1627.

Battese GE, Coelli TJ. 1995. A Model for Technical Efficiency Effects in a Stochastic Frontier Production Function with Panel Data. Empirical Economics 20: 325-332.

Baumol WJ, Bowen WG. 1966. Performing Arts-The Economic Dilemma: A study of problems common to theater, opera, music and dance. The MIT press, Cambridge, MA.

Becker E, Sloan FA. 1985. Hospital ownership and preference. Economic Inquiry 23: 21-36.

Bernet P, Rosko M, Valdmanis V. 2008. The relationship between hospital cost inefficiency and debt ratings. Journal of Health Care Finance 34(4):66-88.

Burgess Jr. JF, Wilson PW. 1996. Hospital ownership and technical inefficiency. Management Science 42: 110-123. 
Carey K. 2003. Hospital cost efficiency and system membership. Inquiry 40 (Spring): 25-38.

Carr W, Feldstein P. 1967. The relationship of cost to hospital size. Inquiry 4: 45-65.

Charnes A, Cooper WW, Rhodes E. 1978. Measuring the efficiency of decision making units. European Journal of Operations Research 2: 429-444.

Chen S. 2006. Productivity Changes in Taiwanese hospitals and the national health insurance. Service Industries Journal 26(4):459-477.

Chirikos T, Sear A. 2000. Measuring hospital inefficiency: A comparison of two approaches. Health Services Research 34: 1389-1408.

Choi J, Park I, Jung I, Dey A. 2015. Complementary effect of patient volume and quality of care on hospital cost efficiency. Healthcare Management Science published First Online: http://link.springer.com/article/10.1007/s10729015-9348-9: 1-11.

Coelen C. 1986. Hospital ownership and comparative hospital costs. In B.H. Gray (Eds.), For-Profit Enterprise in Health Care. Washington, D.C., National Academy Press.

Cortèse L, Hua P. 2002. The effect of the real exchange rate on technological progress. An application to the textile industry in China. CERDI Working Paper 2002/7

Cram P, Pham HH, Bayman L, Vaughan-Sarrazin MS. 2008. Insurance Status of Patients Admitted to Specialty Cardiac and Competing General Hospitals: Are Accusations of Cherry Picking Justified. Medical Care 46(5): 467475.

Cromwell J, Pope G. 1989. Trends in hospital labor and total factor productivity, 1981-86. Health Care Financing Review 10(4): 39-50.

Cylus J, Dickensheets B. 2007. Hospital multifactor productivity: A Presentation and Analysis of Two Methodologies. Health Care Financing Review 29(2): 49-64.

Donabedian A. 2003. Explorations in quality assessment and monitoring. The definition of quality and approaches to its assessment. Ann Arbor: Health Administration Press Vol I:13-15.

Dor A, Farley D. 1996. Payment Source and the Cost of Hospital Care: Evidence from a Multiproduct Cost Function with Multiple Payers. Journal of Health Economics 15(1): 1-22.

Easley D, O’Hara M. 1983. The economic role of the nonprofit firm. Bell Journal of Economics 14: 531-538.

Ellis RP. 1998, Creaming, skimping and dumping: provider competition on the intensive and extensive margins, Journal of Health Economics 17: 537-555. 
Ettner S, Hermann R. 2001. The role of profit status under imperfect information; evidence from the treatment patterns of elderly Medicare beneficiaries hospitalized for a psychiatric diagnoses. Journal of Health Economics 20: 23-49.

Fare R, Grosskopf S, Lovell CAK. 1985. The Measurement of Efficiency of Production, Boston, Kluwer.

Fare R, Grosskopf S, Lovell CAK. 1994. Production Frontiers, Cambridge, University Press.

Folland S, Goodman A, Stano M. 2007. The economics of health and health care (5 $5^{\text {th }}$ ed.). Englewood Cliffs, NJ: Prentice Hall.

Folland S, Hofler R. 2001. How reliable are hospital efficiency estimates? Exploiting the dual to homothetic production. Health Economics 10: 683-698.

Goldstein SM, Ward PT, Keong Leong G, Butler TW. 2002. The effect of location, strategy, and operations technology on hospital performance. Journal of Operations Management 20: 63-75.

Greene W. 2008. The econometric approach to efficiency analysis. In H. Fried, C. Lovell, \& S. Schmidt (Eds.). The measurement of productive efficiency and productivity growth (92-250). Oxford University Press, Oxford, English.

Greenwald L. Cromwell J, Adamache W, Bernard S, Drozd E, Root E, Devers K. 2006. Specialty Versus Community Hospitals: Referrals, Quality, and Community Benefits. Health Affairs 25(1): 106-118.

Grosskopf S, Margaritis D, Valdmanis V. 2001. Comparing teaching and non-teaching hospitals: a frontier approach (teaching vs. non-teaching). Health Care Management Sciences 4: 83-94

Grosskopf S, Margaritis D, Valdmanis V. 2004. Competitive effects on teaching hospitals. European Journal of Operational Research 154(2): 515-525.

Hansmann H. 1980. The role of nonprofit enterprise. Yale Law Journal 89, 835-901.

Hansmann H. 1987. Economic theories of nonprofit organization. In W.W. Powell (Eds.). The Nonprofit Sector: A Research Handbook. Yale University Press, New Haven, CT.

Hansmann H. 1996. The Ownership of Enterprise. Cambridge, Mass, Harvard University Press.

Hollingsworth B. 2008. The measurement of efficiency and productivity of health care delivery. Health Economics 17: $1107-1128$.

Hollingsworth B, Dawson P, Maniadakis N. 1999. Efficiency measurement of health care: a review of nonparametric methods and applications. Health Care Management Science 2(3): 161-172. 
Hollingsworth B, Smith P. 2003. Use of ratios in data envelopment analysis. Applied economics letters 10(11): 733735.

Hollingsworth B, Street A. 2006. The market for efficiency analysis of health care organizations. Health Economics 15(10): 1055-1059.

Huckman R, Barro J. 2005. Cohort turnover and productivity: The July phenomenon in teaching hospitals. NBER Working Paper No. 11182, Harvard Business School, Boston, MA.

Jacobs R. 2001. Alternative methods to examine hospital efficiency: Data envelopment analysis and stochastic frontier analysis. Health Care Management Science 4(2): 103-115.

Kaplan RS, Porter ME. 2011. How to solve the cost crisis in health care. Harvard Business Review 89(9): 47-64. .

Korhonen P, Syrjanen M. 2004. Resource Allocation Based on Efficiency Analysis. Management Science 50(8): 1134-1144.

Kumbhakar SC, Lovell CA. 2000. Stochastic Frontier Analysis. Cambridge, England, Cambridge University Press.

Lee R, Hadley J. The demand for residents. Journal of Health Economics 11(2): 421-447.

Lewin L, Derzon R, Margulies R. 1981. Investor-owneds and nonprofits differ in economic performance. Hospitals 55(13): 52-58.

Linna M. 1998. Measuring hospital cost efficiency with panel data models. Health Economics 7(5): 415-427.

Linna M, Hakkinen U. 1998. A comparative application of econometric frontier and DEA methods for assessing cost efficiency of Finnish hospitals. Developments in Health Economics and Public Policy 6: 167-187.

Linna M, Hakkinen U. 2006. Reimbursing for the costs of teaching and research in Finnish hospitals: a stochastic frontier analysis. International Journal of Health Care Finance \& Economics 6(1):83-97.

Long M, Chesney J, Ament R, DesHarnais S, Fleming S, Kobrinski E, Marshall B. 1987. The effect of PPS on hospital product and productivity. Medical Care 25(6): 528-538.

Mathur SK. 2007. Indian IT industry: a performance analysis and a model for possible adoption. MPRA paper no. 2368

Meeusen W, van den Broeck J. 1977. Efficiency estimation from Cobb-Douglas production functions with composed error. International Economic Review 18: 435-444.

Mutter RL, Rosko MD, Wong HS. 2008. Measuring Hospital Inefficiency: The Effects of Controlling for Quality and Patient Burden of Illness. Health Services Research 43(6): 1992-2013. 
Neely S, McInturff W. 1998. What Americans Say About the Nation's Medical Schools and Teaching Hospitals. Report on Public Opinion Research, Part II. Association of American Medical Colleges, Washington, DC.

Nelson R, Krashinsky M. 1973. Two major issues of public policy: Public policy and organization of supply. In R. Nelson and D. Young (Eds.). Public Subsidy for Day Care of Young Children. Lexington, Mass., DC Heath.

Newhouse J. 1994. Frontier estimation: How useful a tool for health economics? Journal of Health Economics 13: 317-322.

Oh Y, Oh D, Lee J. 2016. A sequential global Malmquist productivity index: Productivity growth index for unbalanced panel data considering the progressive nature of technology. Empirical Economics (forthcoming) online: http://link.springer.com/article/10.1007/s00181-016-1104-6.

O’Neill L, Rauner M, Heidenberger K, Kraus M. 2008. A cross-national comparison and taxonomy of DEA-based hospital efficiency studies. Socio-Economic Planning Sciences 42(3): 158-189.

Pattison RV. 1986. Response to financial incentives among investor-owned and not-for-profit hospitals: An analysis based on California data 1978-82. In B.H. Gray (Eds.), For-Profit Enterprise in Health Care. Washington, D.C., National Academy Press.

Pattison RV, Katz HM. 1983. Investor-owned and not-for-profit hospitals: A comparison based on California data. New England Journal of Medicine 309: 347-353.

Pisano G, Bohmer R, Edmondson A. 2001. Organizational differences in rates of learning: Evidence from the adoption of minimally invasive cardiac surgery. Management Science 47(6): 752-768.

Porter ME, Teisberg EO. 2004, Redefining competition in health care. Harvard Business Review Jun 2004: 65-76.

Preyra C, Pink G. 2006. Scale and scope efficiencies through hospital consolidations. Journal of Health Economics 25(6): 1049-68.

Romano P, Mutter R. 2004. The evolving science of quality measures for hospitals: Implications for studies of competition and consolidation. International Journal of Health Care Finance \& Economics 4:131-157.

Rose-Ackerman S. 1996. Altruism, nonprofits, and economic theory. Journal of Economic Literature 34: 701-728.

Rosko MD. 1999. Impact of internal and external environmental pressures on hospital inefficiency. Health Care Management Science 2: 64-78.

Rosko MD. 2001. Cost efficiency of U.S. hospitals: A stochastic frontier approach. Health Economics 10: 539-551.

Rosko MD. 2004. Performance of U.S. Teaching Hospitals: A Panel Analysis of Cost Inefficiency. Health Care Management Science 7(16): 7-16. 
Rosko MD, Mutter RL. 2008. Stochastic frontier analysis of hospital inefficiency: A review of empirical issues and an assessment of robustness. Medical Care Research and Review 65: 131-166.

Rosko MD, Mutter RL. 2011. What have we learned from the application of stochastic frontier analysis to U.S. hospitals? Health Care Research and Review 68(1): 75S-100S.

Santerre RE, Pepper D. 2000. Survivorship in the US hospital service industry. Managerial and Decision Economics 21: 181-189.

Shortell S, O’Brien J, Carman J, Foster R, Hughes E, Boerstler H, O'Connor E. 1995. Assessing the impact of continuous quality improvement/total quality management: concept versus implementation. Health Services Research 30(2): 377-401.

Sloan FA. 2000. Handbook of Health Economics Vol. 1, Part B, 1141-1174, Chapter 21 Not-for-profit ownership and hospital behavior.

Soteriou A, Zenios SA. 1999. Quality, Profitability and Efficiency in the provision of banking services. Management Science 45:1221-1238.

Stevens LM. 2004. Academic health centers. Journal of the American Medical Association 292(9): 1134.

Taylor D, Whellan D, Sloan F. 1999. Effects of admission to a teaching hospital on the cost and quality of care for Medicare beneficiaries. New England Journal of Medicine 340: 293-302.

Theokary C, Ren J. 2011. An Empirical Study of the Relations between Hospital Volume, Teaching Status and Service Quality. Production and Operations Management 20(3): 303-318.

Tucker A, Edmondson A. 2003. Why hospitals don't learn from failures: Organizational ad psychological dynamics that inhibit system change. California Management Review 45(2): 55-72.

Weisbrod BA. 1977. The Voluntary Nonprofit Sector: An Economic Analysis. Lexington, Mass., DC Heath.

Weisbrod BA. 1988. The Nonprofit Economy. Cambridge, Mass., Harvard University Press.

Zhuo L, Choo YY, Oum TH. 2013. Efficiency Benchmarking of North American Airports: Comparative Results of Productivity Index, Data Envelopment Analysis and Stochastic Frontier Analysis. Journal of Transportation Research Forum 52(1): 47-67.

Zuckerman S, Hadley J, Iezzoni L. 1994. Measuring hospital efficiency with frontier cost functions. Journal of Health Economics 13(3): 255-280. 
Table 1. Debatable results from comparative studies on hospital efficiency based on groups of hospitals.

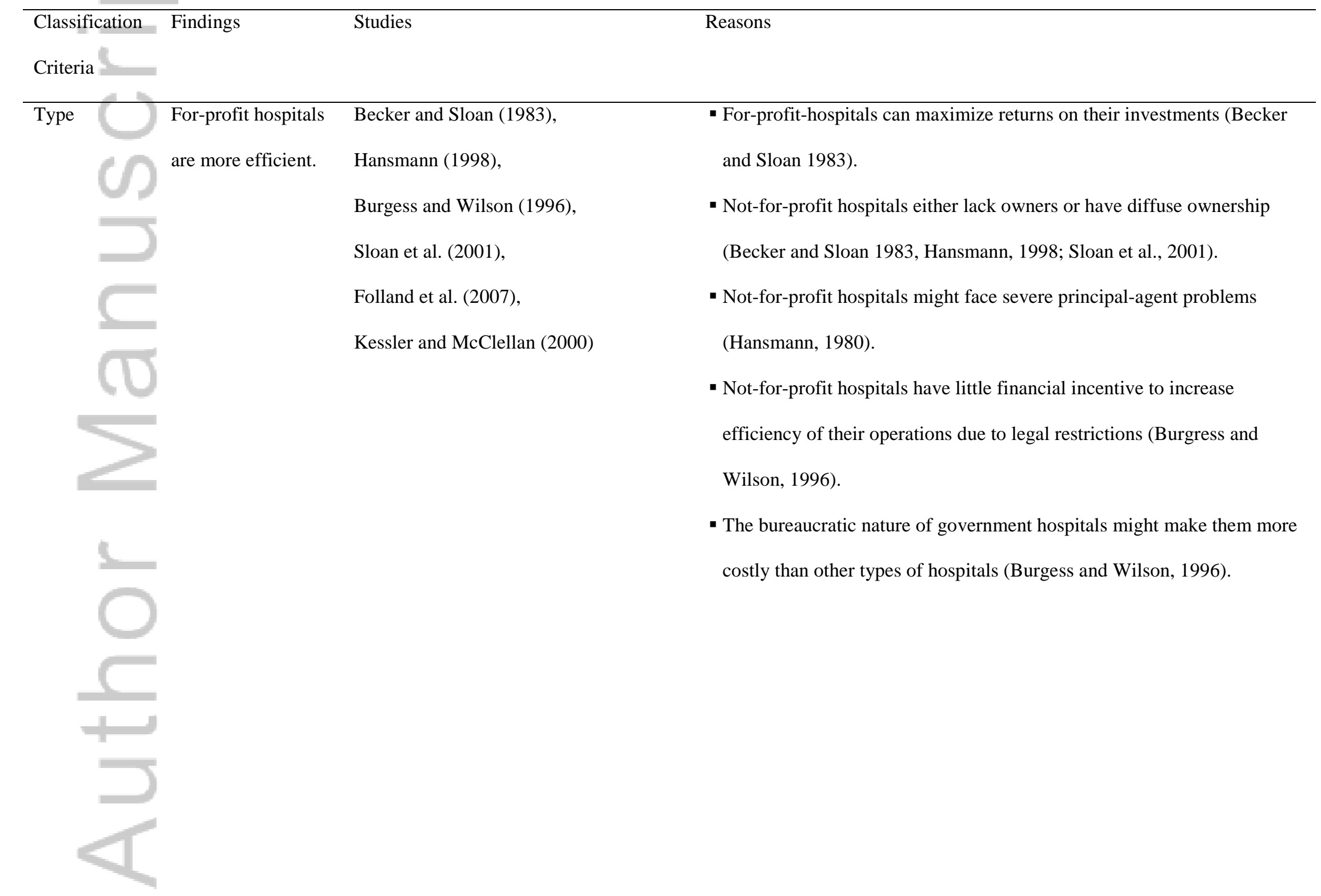

This article is protected by copyright. All rights reserved. 


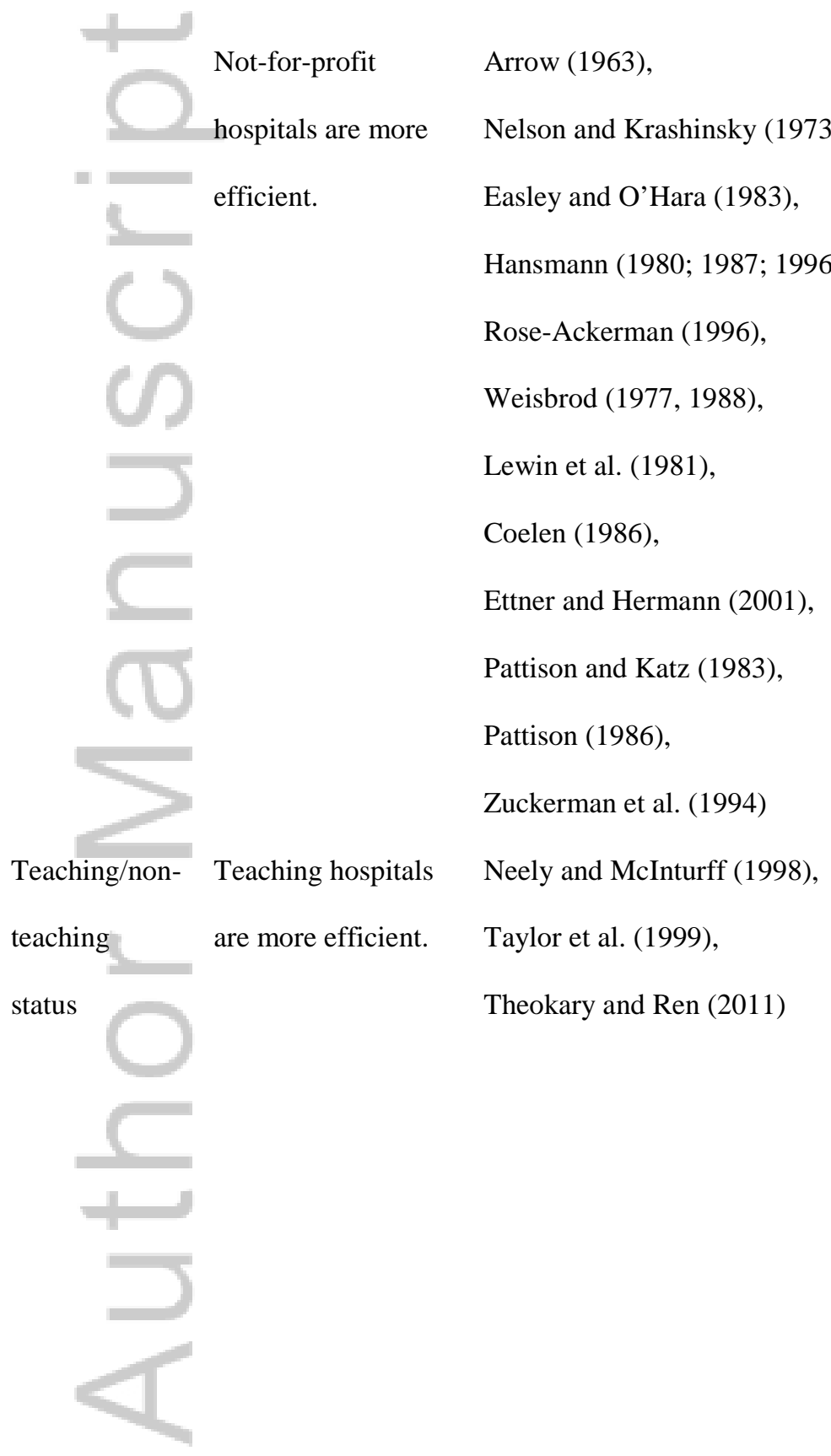

- Non-profit hospitals are more responsive to incomplete markets (Arrow 1963, Nelson and Krashinsky 1973, Easley and O’Hara 1983, Hansmann 1980, 1987, 1996, Rose-Ackerman 1996, Weisbrod 1977, 1988).

- For-profit hospitals have higher costs than not-for-profit hospitals

(Lewin et al., 1981; Coelen, 1986; Ettner and Hermann, 2001; Pattison and Katz, 1983; Pattison, 1986; Zuckerman, et al., 1994).

- Residents' autonomy lowers costs by partially replacing physicians with residents (Theokary and Ren, 2011).

- Patient care tends to be of higher quality in teaching hospitals (Taylor et al., 1999). 
- Teaching hospitals tend to attract talented physicians and provide specialized services (Neely and McInturff, 1998).

- Rare diseases are treated and biomedical research conducted in teaching hospitals (Neely and McInturff, 1998)

- Teaching hospitals are more costly due to the cost of providing medical education and research (Hollingsworth, 2008; Hollingsworth and Smith, 2003; Grosskopf et al., 2004).

- Other reasons of higher cost of teaching hospitals include but are not limited to the (1) increased use of ancillary services; (2) longer stays; (3) urban location of most teaching hospitals; (4) use of highly sophisticated forms of technology; (5) extra tests ordered by residents; and (6) larger volumes of uncompensated care provided (Grosskopf et al., 2001; Lee and Hadley, 1985)

- Bigger hospitals exhibit higher performance than smaller hospitals mainly due to the learning effect and economies of scale (Porter and Teisberg, 2004; Carr and Feldstein, 1967; Preyra and Pink, 2006). 


\section{Smaller hospitals} are more efficient.

Pisano et al. (2001)

Shortell et al. (1995),

Tucker and Edmondson (2003)
- Large hospitals must conduct large-scale communication and coordination among various medical units (Pisano et al, 2001; Shortell et al., 1995; Tucker and Edmondson, 2003).

This article is protected by copyright. All rights reserved. 
Table 2. Hospitals demographic information.

\begin{tabular}{|c|c|c|c|c|c|}
\hline Variables & Median & Mean & S.D. & Min. & Max. \\
\hline Number of beds & 231 & 290.3 & 210.7 & 28 & 2,236 \\
\hline \multicolumn{6}{|l|}{ Number of employees } \\
\hline on payroll & 849.6 & $1,368.3$ & $1,635.0$ & 32.4 & $20,545.1$ \\
\hline Admissions & $7,260.0$ & $10,592.4$ & $10,432.0$ & 101.0 & $105,339.0$ \\
\hline Post-admission days & $16,462.0$ & $26,981.3$ & $32,543.3$ & 124.0 & $407,470.0$ \\
\hline Number of outpatients & $126,195.0$ & $195,081.2$ & $42,002.0$ & $2,527.0$ & $4,311,183.0$ \\
\hline $\begin{array}{l}\text { Labor costs (US\$, } \\
\text { thousands) }\end{array}$ & $58,909.2$ & $102,598.3$ & $138,122.4$ & $1,395.8$ & $2,129,251.5$ \\
\hline $\begin{array}{l}\text { Capital costs (US\$, } \\
\text { thousands) }\end{array}$ & $5,992.1$ & $10,492.3$ & $14,688.7$ & 3.1 & $246,365.0$ \\
\hline Total operating & & & & & \\
\hline $\begin{array}{l}\text { expenses } \\
\text { (US\$, thousands) }\end{array}$ & $132,300.0$ & $224,795.6$ & $160,720.8$ & $2,738.9$ & $3,721,000.0$ \\
\hline
\end{tabular}

* S.D.: standard deviation; Min: minimum; Max: maximum. ** All the values are from 2011 before the CMI adjustment. 
Table 3. Hospital demographic information by group.

\begin{tabular}{|c|c|c|}
\hline Hospital Classification & Number & Percentage $(\%)$ \\
\hline \multicolumn{3}{|l|}{ Hospital type } \\
\hline Non-profit & 956 & 65.0 \\
\hline Proprietary & 203 & 13.8 \\
\hline Government & 312 & 21.2 \\
\hline \multicolumn{3}{|l|}{ Teaching/non-teaching status } \\
\hline Teaching & 495 & 33.7 \\
\hline Non-teaching & 976 & 66.3 \\
\hline \multicolumn{3}{|l|}{ Size (based on number of beds) } \\
\hline Less than 50 & 138 & 9.4 \\
\hline $50-99$ & 224 & 15.2 \\
\hline $100-199$ & 432 & 29.4 \\
\hline $200-499$ & 526 & 35.8 \\
\hline 500-higher & 151 & 10.3 \\
\hline \multicolumn{3}{|l|}{ Region (states) } \\
\hline Mid-Atlantic (CT, MA, ME, NH, NJ, NY, PA, RI, VT) & 198 & 13.5 \\
\hline South Atlantic (DC, DE, FL, GA, MD, NC, SC, VA, WV) & 256 & 17.4 \\
\hline East-north central (IL, IN, MI, OH, WI) & 237 & 16.1 \\
\hline West-north central (IA, KS, MN, MO, ND, NE, SD) & 127 & 8.6 \\
\hline East-south central (AL, KY, MS, TN) & 150 & 10.2 \\
\hline West-south central (AR, LA, OK, TX) & 162 & 11.0 \\
\hline
\end{tabular}


Table 4. Efficiency by model.

\begin{tabular}{|c|c|c|c|c|c|c|}
\hline & \multicolumn{3}{|c|}{ SFA Time-varying Decay Model } & \multicolumn{3}{|c|}{ DEA Model } \\
\hline & Median & Mean & Std. Dev. & Median & Mean & Std. Dev. \\
\hline 001 & 0.4954 & 0.5139 & 0.1174 & 0.5879 & 0.6101 & 0.1666 \\
\hline 002 & 0.4863 & 0.5045 & 0.1149 & 0.6092 & 0.6291 & 0.1653 \\
\hline 2003 & 0.4775 & 0.4951 & 0.1128 & 0.5858 & 0.6163 & 0.1757 \\
\hline 2004 & 0.4685 & 0.4861 & 0.1102 & 0.5699 & 0.6047 & 0.1775 \\
\hline 2005 & 0.4601 & 0.4774 & 0.1074 & 0.6053 & 0.6294 & 0.1772 \\
\hline 2006 & 0.4519 & 0.4689 & 0.1057 & 0.5828 & 0.6203 & 0.1735 \\
\hline 2007 & 0.4437 & 0.4603 & 0.1041 & 0.5848 & 0.6046 & 0.1749 \\
\hline 008 & 0.4356 & 0.4521 & 0.1013 & 0.5758 & 0.5972 & 0.1694 \\
\hline 2009 & 0.4281 & 0.4439 & 0.0994 & 0.5954 & 0.6314 & 0.1797 \\
\hline 2010 & 0.4204 & 0.4361 & 0.0973 & 0.5834 & 0.6146 & 0.1771 \\
\hline 2011 & 0.4130 & 0.4283 & 0.0951 & 0.5943 & 0.6218 & 0.1792 \\
\hline
\end{tabular}




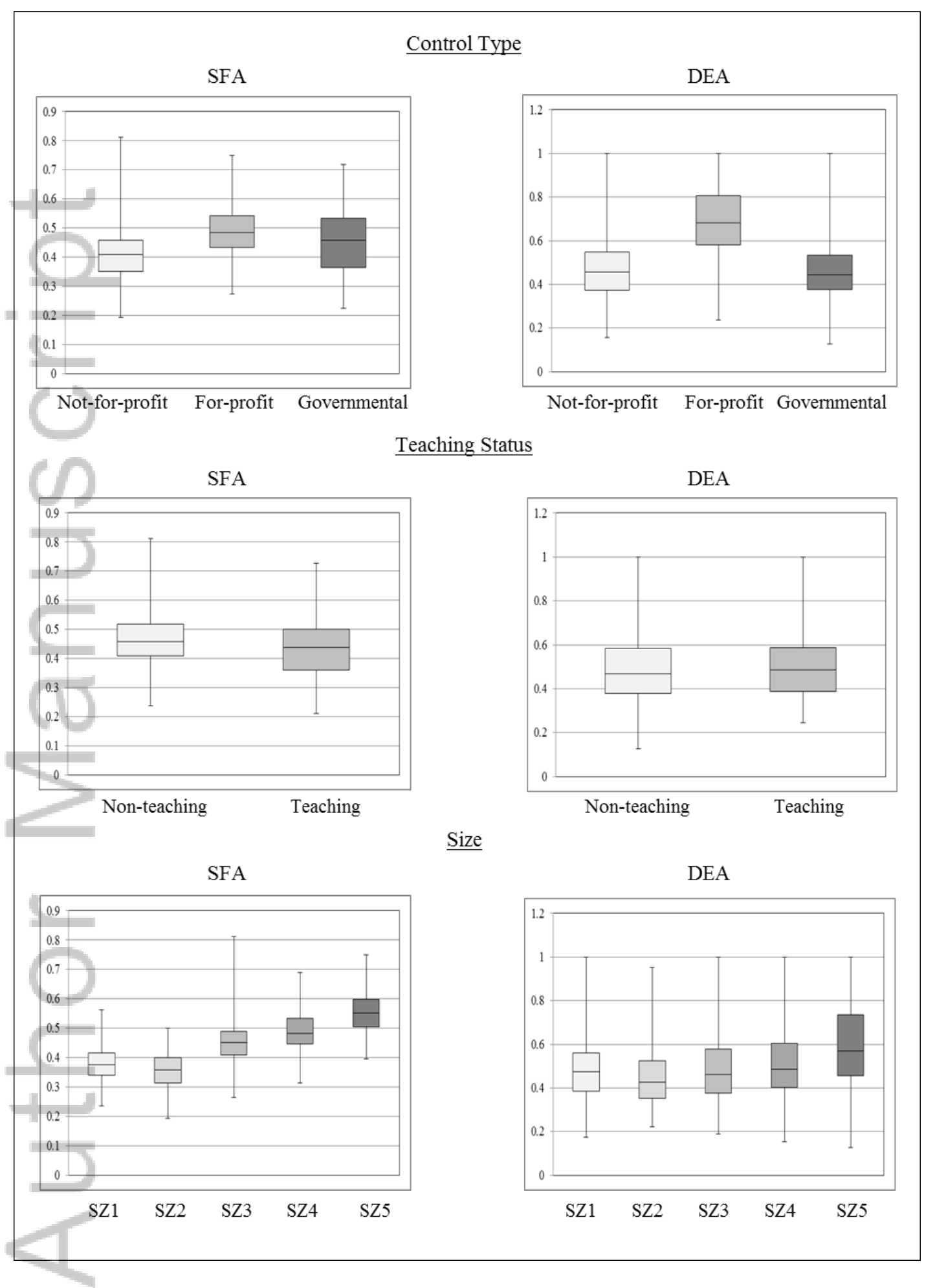


Fig. 1. Box-plot of efficiency scores by hospital type, teaching status, and size in 2011.

* SZ1: (NOB < 50); SZ2: (NOB: 50-99); SZ3: (NOB: 100-199); SZ4: (NOB: 200-499); SZ5: (NOB Z 500), where NOB is the number of bed.

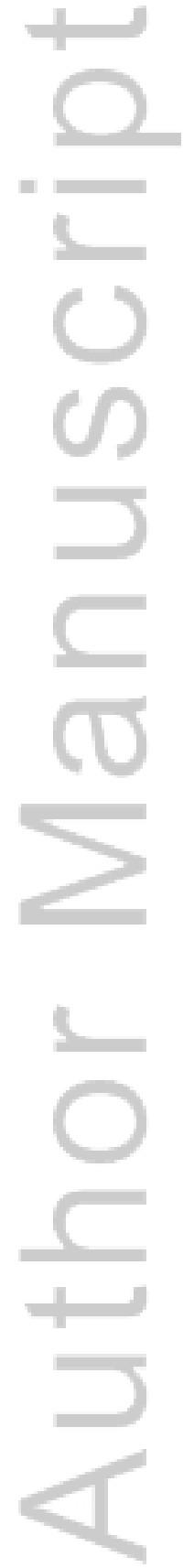

